Bài báo khoa hoc

\title{
Đánh giá kĩ năng dự báo quỹ đạo bão của hệ thống mô hình tổ họp
}

\author{
Trần Quang Năng ${ }^{1 *}$, Trần Tân Tiến ${ }^{2}$
}

${ }^{1}$ Trung tâm Dự báo khí tượng thủy văn quốc gia; trannang030984@ gmail.com;

${ }^{2}$ Trường Đại học khoa học tự nhiên Hà Nội; tientt49@gmail.com

* Tác giả liên hệ: trannang030984@gmail.com; Tel.: +84-936328136

Ban Biên tập nhận bài: 25/7/2020; Ngày phản biện xong: 18/8/2020; Ngày đăng bài: $25 / 9 / 2020$

Tóm tắt: Bài báo trình bày phương pháp đánh giá kĩ năng dự báo quỹ đạo cho hệ thống tổ hợp để đánh giá thông tin xác suất dự báo được vị trí đi qua của cơn bão (strike probability map) - hay sai số xác suất của quỹ đạo. Một số kết quả đã được áp dụng cho hai hệ thống dự báo tổ hợp khu vực SREPS (dựa trên mô hình WRF-ARW, WRF-NMM và HRM, sử dụng đa đầu vào GFS, GSM, GME, GEM và NOGAPS) và tổ hợp toàn cầu Var_EPS của Trung tâm Dự báo thời tiết hạn vừa Châu Âu (ECMWF) cho một số cơn bão hoạt động trên Biển Đông và ảnh hưởng đến đất liền Việt Nam trong giai đoạn 2012-2016. Đối với dự báo tất định từ sản phẩm dự báo trung bình tổ hợp, các kết quả cho thấy việc giảm sai số khi so sánh với dự báo quỹ đạo của từng thành phần đơn lẻ đối với cả hệ thống SREPS và Var_EPS. Áp dụng phương pháp tính toán sai số xác suất dựa trên điểm số BS đã cho thấy kĩ năng dự báo quỹ đạo từ tổ hợp toàn cầu ổn định hơn so với dự báo tổ hợp khu vực.

Từ khóa: Dự báo tổ hợp; Đánh giá kĩ năng dự báo xác suất quĩ đạo bão; SREPS; Var_EPS.

\section{1. Đặt vấn đề}

Dự báo tổ hợp (Ensemble Forecast-EF) là một tập hợp dự báo xác định tại cùng một thời điểm (có thể được bắt đầu từ các điều kiện ban đầu khác nhau [1], thời điểm bắt đầu dự báo khác nhau, hoặc dựa trên các mô hình khác nhau) và hướng đến 3 mục đích: i) Tăng cường chất lượng dự báo thông qua trung bình tổ hợp (dự báo tất định từ dự báo tổ hợp); ii) Cung cấp một chỉ số định lượng về độ tin cậy của dự báo (dự báo kỹ năng dự báo) và iii) Làm cơ sở cho dự báo xác suất (dự báo xác suất từ dự báo tổ hợp). Lý thuyết $\mathrm{EF}$ được đặt nền móng từ những năm 70 và bắt đầu đưa vào ứng dụng đầu những năm 90 của thế kỷ trước với mục đích sử dụng đầu tiên áp dụng cho dự báo hạn vừa trên quy mô hành tinh. Một số hệ thống dự báo tổ hợp (Ensemble Prediction System-EPS) nghiệp vụ điển hình như tại Trung tâm quốc gia dự báo môi trường của Mỹ (NCEP-National Center for Enviromental Prediction) được sử dụng từ năm 1992 dựa trên phương pháp nuôi nhiễu động phát triển nhanh (BGM-Breeding of Growing Mode) để tạo tập hợp các trường ban đầu khác nhau cho mô hình toàn cầu T126 với 28 mực thẳng đứng và tích phân tới 180 giờ [2], tại Trung tâm dự báo thời tiết hạn vừa Châu Âu (ECMWF-European Center for Medium-range Weather Forecasts), EPS cũng được đưa vào nghiệp vụ từ năm 1992 bằng việc sử dụng phương pháp tách vector kỳ dị để tạo nhiễu động ban đầu [3]. EPS này hiện nay có tới 51 dự báo thành phần, thực hiện dự báo hàng ngày và cung cấp kết quả cho các nước trong Cộng đồng Châu Âu là thành viên của ECMWF. Ở quy mô vừa với các ứng dụng dựa trên mô hình khu vực 
phân giải cao, các hệ thống tổ hợp quy mô vừa cũng được thiết lập, một trong những nghiên cứu điển hình trong vấn đề xây dựng hệ thống tổ hợp cho hạn 3-5 ngày [4].

Ứng dụng của $\mathrm{EF}$ đối với dự báo thời tiết nói chung và riêng dự báo bão đã mang lại những thông tin hết sức hữu ích như độ tán của dự báo quỹ đạo hay dự báo cường độ bão, qua đó cho phép xây dựng các kịch bản ứng phó và đánh giá được mức độ rủi ro trong việc ứng dụng các sản phẩm dự báo bão từ mô hình số. Hình 1 minh họa dự báo quỹ đạo bão tổ hợp từ hệ thống tổ hợp Var_EPS của ECMWF (a) và hệ thống tổ hợp khu vực SREPS (b) đang chạy nghiệp vụ tại Trung tâm Dự báo khí tượng thủy văn quốc gia cho cơn bão số 12 (Damrey) năm 2017.
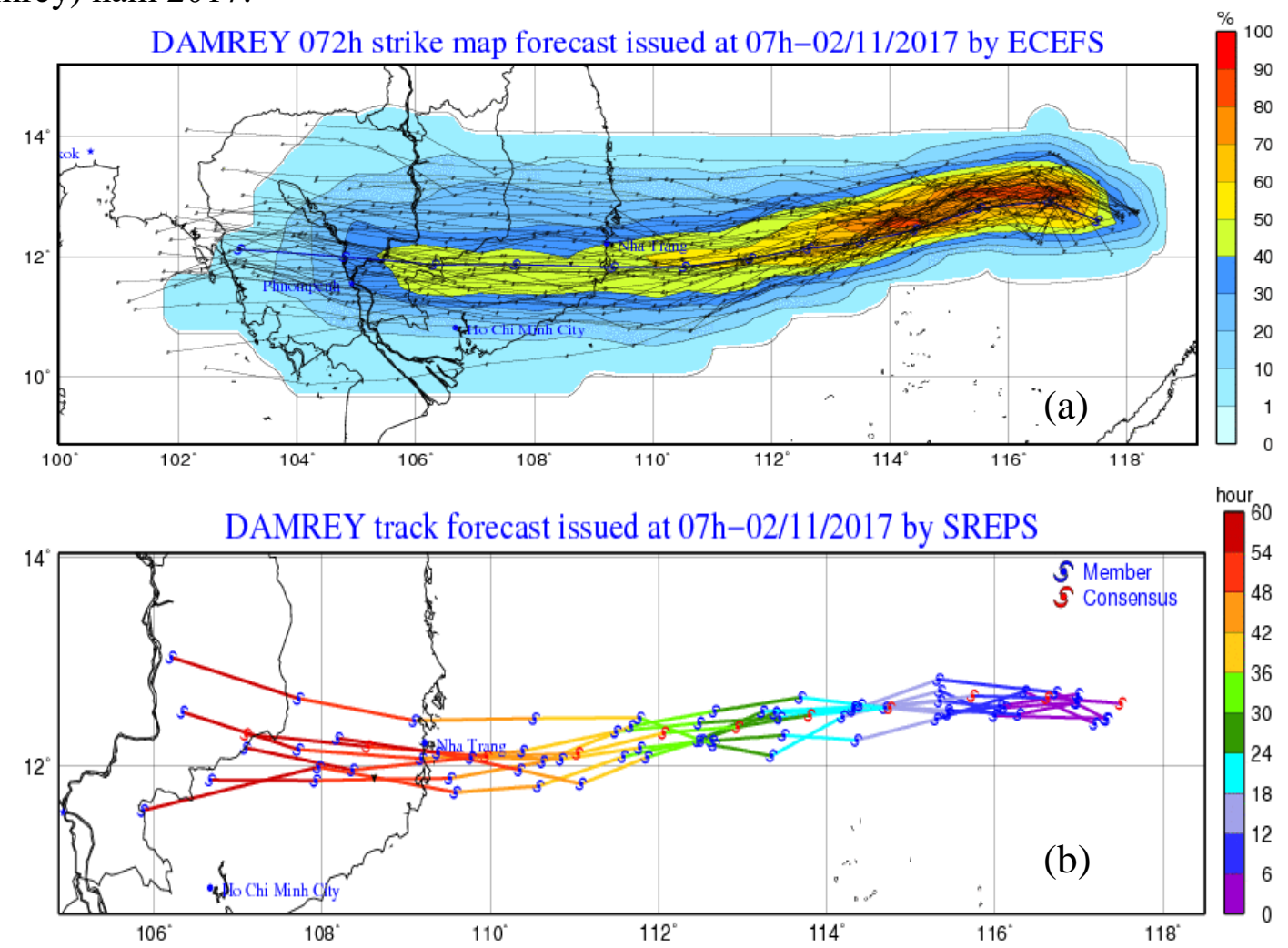

Hình 1. Dự báo cơn bão số 12 (Damrey) năm 2017 từ các hệ thống dự báo tổ hợp SREPS (trái) và Var_EPS (phải).

Việc đánh giá dự báo quỹ đạo bão từ dự báo tổ hợp khác với việc đánh giá dự báo quỹ đạo bão từ dự báo tất định (01 mô hình), ngoài việc đánh giá được sai số dự báo trung bình tổ hợp (ensemble mean) với ý nghĩa như một dự báo tất định, các thông tin liên quan đển độ tán của dự báo tổ hợp cũng cần được đánh giá, qua đó cho phép đánh giá được mức độ tin cậy của từng hệ thống dự báo tổ hợp trong ứng dụng dự báo bão.

Với mục tiêu đánh giá dự báo quỹ đạo bão từ dự báo tổ hợp, nghiên cứu này sẽ trình bày phương pháp đánh giá trong mục 2 cùng một số kết quả đánh giá cho hệ thống dự báo tổ hợp khu vực SREPS gồm 15 thành phần dựa trên mô hình WRF (NCEP, Mỹ) và HRM (DWD, Đức) và hệ thống dự báo tổ hợp toàn cầu Var_EPS (ECMWF). Mô tả về hệ thống dự báo tổ hợp được trình bày trong phần 2 cùng phương pháp đánh giá kĩ năng dự báo xác suất quỹ đạo bão. Các kết quả chính được đưa ra trong phần 3 .

\section{Phương pháp đánh giá}

\subsection{Sai số dụ báo quỹ đạo}

Sai số dự báo quỹ đạo DPE (Direct Possition Error) là khoảng cách giữa vị trí tâm bão quan trắc (từ số liệu quỹ đạo chuẩn, nghiên cứu sử dụng dữ liệu từ Trung tâm khí tượng quốc tế chịu trách nhiệm cho khu vực Tây Bắc Thái Bình Dương đặt tại Tokyo-RSMC Tokyo) và 
vị trí tâm bão dự báo được lấy tại từng hạn dự báo. Với $\mathrm{R}_{\mathrm{e}}$ là bán kính trái đất, kinh độ (lat) và vĩ độ (lon) của tâm bão dự báo từ mô hình, DPE được xác định trong hệ tọa độ cầu theo công thức (1) như sau [5]:

$$
\begin{aligned}
& D P E=R_{e} \times \operatorname{Arccos}\left\{\sin \left(\text { lat }_{\mathrm{RSMC}}\right) \times \sin \left(\text { lat }_{\text {dự báo }}\right)+\cos \left(\text { lat }_{\mathrm{RSMC}}\right)\right.
\end{aligned}
$$

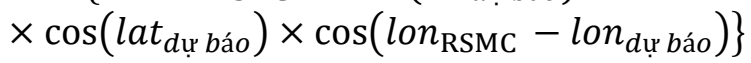

\subsection{Phương pháp đánh giá kĩ năng dụ báo xác suất tổ hợp}

Gọi giá trị dự báo tại một hạn xác định của $\mathrm{N}$ thành phần dự báo là $\mathrm{X}_{1}, \ldots, \mathrm{X}_{\mathrm{N}}$, khi đó trung bình tổ hợp $\bar{X}$ và độ tán $\sigma_{X}$ tương ứng được tính theo công thức (2) và (3) như sau [6]:

$$
\bar{X}=\frac{1}{N} \sum_{k=1}^{N} X_{k}
$$

Với đặc trưng trung bình tổ hợp ta có thế áp dụng các sai số trung bình, sai số trung bình tuyệt đối sau khi có giá trị trung bình tổ hợp và xem như đây là dự báo từ mô hình. Đối với đặc trưng thứ hai thể sự khác biệt giữa dự báo tổ hợp và dự báo tất định. Dự báo từ các thành phần được sử dụng để đưa ra kết quả dưới dạng xác suất và có thể hiện kĩ năng của hệ thống dự báo tổ hợp cho trước. Ngoài ra, độ tán của hệ tổ hợp với khả năng phủ được tối đa không gian nghiệm thực sẽ đặc trưng cho một hệ tổ hợp có độ tin cậy cao hoặc hệ tổ hợp có kĩ năng dự báo. Đối với đánh giá kĩ năng dự báo quỹ đạo cho hệ thống tổ hợp, khi đánh giá sản phẩm dự báo quỹ đạo từ hệ thống tổ hợp của ECMWF [8-9] để đánh giá sản phẩm dự báo tổ hợp bão tại Cơ quan khí tượng Vương quốc Anh [9]. Các công trình này đề xuất sử dụng điểm số BS (Brier Score) để đánh giá xác suất dự báo được vị trí đi qua của cơn bão (Strike probability map) hay sai số xác suất của quỹ đạo. Khi áp dụng cần phải thực hiện quá trình tiền xử lý để biến đổi dự báo xác suất quỹ đạo thành dạng đánh giá hiện tượng dự báo. Quá trình xử lý này phát sinh khái niệm về vòng tròn tin cậy của dự báo quỹ đạo. Để minh họa phương pháp một cách cụ thể, ứng với một vị trí quan trắc bão ở hạn dự báo $24 \mathrm{~h} l a ̀$ $15^{\circ} \mathrm{N}$; $110^{\circ} \mathrm{E}$ và ta định nghĩa một vòng tròn tin cậy ở hạn $24 \mathrm{~h}$ có bán kính là $50 \mathrm{~km}$, khi đó bất kì thành phần dự báo nào dự báo vị trí ở hạn $24 \mathrm{~h}$ rơi vào bên trong đường tròn này được gán là có xảy ra hiện tượng dự báo đúng. Một minh họa tổng quát được đưa ra trong Hình đối với trường hợp dự báo tổ hợp gồm 21 thành phần cho cơn bão Krosa lúc $12 z$ ngày 30/10/2013. Thông tin về hệ thống dự báo 21 thành phần được tham khảo tại [10].

Với minh họa theo hình 2 trên, trong tổng số 21 thành phần dự báo, nếu có 7 thành phần dự báo đi vào vòng tròn nêu trên thì xác suất dự báo là $7 / 21$, xấp xỉ $33 \%$. Các giá trị điển hình cho bán kính vòng tròn để xác định quỹ đạo dự báo đúng được đặt khác nhau tùy theo từng hạn dự báo, ví dụ đối với hạn dự báo $120 \mathrm{~h}$ bán kính dùng để đánh giá sản phẩm ECMWF là $65 \mathrm{~nm}$, xấp xỉ $130 \mathrm{~km}$ [9]. Thông thường các giá trị bán kính này có thể lấy xấp xỉ bằng $25 \%-30 \%$ so với các sai số trung bình quỹ đạo điển hình hiện nay, cụ thể với hạn trước $72 \mathrm{~h}$ là $30 \mathrm{~km}, 96 \mathrm{~h}$ là $100 \mathrm{~km}$ và $120 \mathrm{~h}$ là $120 \mathrm{~km}$ [8-9].

Việc xem xét kĩ năng dự báo xác suất sẽ bổ sung thêm thông tin về chất lượng của hệ thống tổ hợp bên cạnh việc đánh giá trực tiếp như sai số trung bình tuyệt đối của các đặc trưng trung bình tổ hợp. Ví dụ tại một thời điểm dự báo, có thể có $40 \%$ số thành phần dự báo tốt vị trí, tuy nhiên $60 \%$ còn lại có sai số rất lớn sẽ kéo theo sai số lớn của chỉ số trung bình tuyệt đối nhưng trong tính toán sai số kĩ năng rõ ràng vẫn giữ được thông tin nắm bắt được của các thành phần tổ hợp này. Sau khi có các giá trị xác suất rơi vào từng vòng tròn tin cậy, sai số xác suất sẽ được xác định từ chỉ số $B S$ (Brier Score) có dạng:

$$
B S=\frac{1}{N} \sum_{k=1}^{N}\left(p_{k}-o_{k}\right)^{2}
$$

Trong đó $N$ là số trường hợp dự báo, $\mathrm{p}_{\mathrm{k}}$ là xác suất dự báo của trường hợp dự báo thứ $\mathrm{k}$ đối với quan trắc $o_{k}$. Ví dụ nếu áp dụng tính toán chỉ số BS trong dự báo xảy ra hiện tượng mưa, quan trắc $\mathrm{o}_{\mathrm{k}}$ sẽ bao gồm cả hiện tượng xảy ra (bằng 1 ) và không xảy ra (bằng 0 ), tuy 
nhiên đối với đánh giá quỹ đạo bão chỉ xem xét trên các vị trí bão đi qua theo quỹ đạo chuẩn xác định được, hay hiện tượng quan trắc là luôn xảy ra để tham chiếu tính toán xác suất dự báo $p_{k}$. Chỉ số $B S$ là hoàn hảo khi có giá trị bằng 0 và có kĩ năng thấp khi bằng 1 .

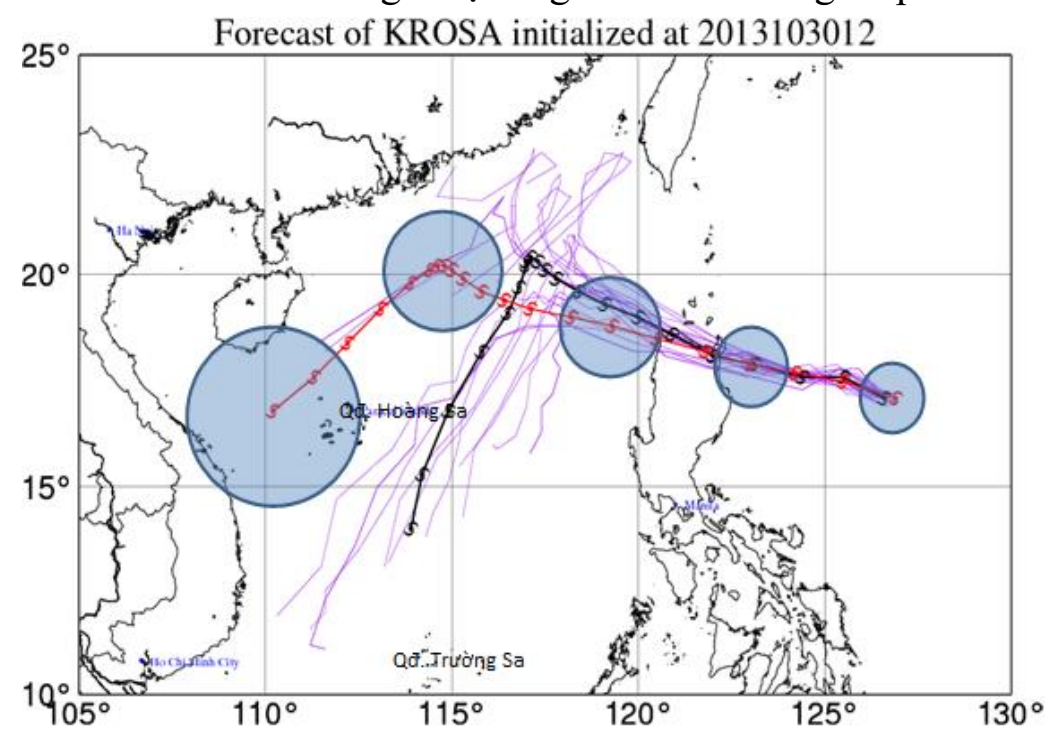

Hình 2. Minh họa các vòng tròn để chuyển đổi dự báo quỹ đạo thành hiện tượng dự báo đúng sai phục vụ tính toán chỉ số BS. Đường đỏ là quỹ đạo bão chuẩn, đường đen là quỹ đạo trung bình tổ hợp, đường tím là dự báo quỹ đạo từ các thành phần tổ hợp [10].

\subsection{Danh sách cơn bão đánh giá}

Trong nghiên cứu sử dụng số liệu quỹ đạo bão chuẩn của Trung tâm Dự báo khí tượng thủy văn quốc gia. Chi tiết các cơn bão và các thời điểm dự báo được đưa ra trong bảng 1 và minh họa cụ thể quỹ đạo bão chuẩn trong hình 3. Các đánh giá thực hiện đến hạn dự báo 3 ngày (72h).

Bảng 1. Danh sách cơn bão năm 2012-2016.

\begin{tabular}{|c|c|c|c|}
\hline & Tên bão & Thời điểm bắt đầu dụ báo & Thò̀i điểm kết thúc dụ̣ báo \\
\hline \multirow{8}{*}{$\frac{\sim}{i}$} & TALIM & 2012061800 & 2012061900 \\
\hline & DOKSURI & 2012062800 & 2012062900 \\
\hline & VICENTE & 2012072012 & 2012072400 \\
\hline & KAI-TAK & 2012081500 & 2012081700 \\
\hline & TEMBIN & 2012082312 & 2012082612 \\
\hline & GAEMI & 2012092900 & 2012100512 \\
\hline & SON-TINH & 2012102412 & 2012102800 \\
\hline & BOPHA & 2012120500 & 2012120800 \\
\hline \multirow{13}{*}{$\stackrel{m}{\stackrel{n}{\sigma}}$} & WUKONG & 2012122700 & 2012122800 \\
\hline & SONAMU & 2013010312 & 2013010412 \\
\hline & BEBINCA & 2013062100 & 2013062212 \\
\hline & RUMBIA & 2013070100 & 2013070100 \\
\hline & CIMARON & 2013071712 & \\
\hline & JEBI & 2013073100 & 2013080212 \\
\hline & MANGKHUT & 2013080612 & 2013080700 \\
\hline & UTOR & 2013081112 & 2013081412 \\
\hline & USAGI & 2013092012 & 2013092200 \\
\hline & WUTIP & 2013092712 & 2013093000 \\
\hline & NARI & 2013101112 & 2013101412 \\
\hline & KROSA & 2013103100 & 2013110312 \\
\hline & HAIYAN & 2013110812 & 2013110912 \\
\hline ㄱ. & HAGIBIS & 2014061412 & \\
\hline
\end{tabular}




\begin{tabular}{|c|c|c|c|}
\hline & Tên bão & Thời điểm bắt đầu dụ báo & Thời điểm kết thúc dự báo \\
\hline \multirow{11}{*}{$\frac{n}{\stackrel{n}{d}}$} & RAMMASUN & 2014071512 & 2014071900 \\
\hline & KALMAEGI & 2014091400 & 2014091612 \\
\hline & FUNG-WONG & 2014091900 & \\
\hline & SINLAKU & 2014112800 & 2014112812 \\
\hline & HAGUPIT & 2014120812 & 2014121100 \\
\hline & JANGMI & 2014123012 & 2014123100 \\
\hline & KUJIRA & 2015062100 & 2015062312 \\
\hline & LINFA & 2015070500 & 2015070812 \\
\hline & VAMCO & 2015091400 & \\
\hline & DUJUAN & 2015092800 & \\
\hline & MUJIGAE & 2015100200 & 2015100400 \\
\hline \multirow{11}{*}{$\stackrel{0}{\stackrel{0}{0}}$} & MELOR & 2015121500 & \\
\hline & NEPARTAK & 2016070712 & 2016070800 \\
\hline & MIRINAE & 2016072612 & \\
\hline & NIDA & 2016073100 & 2016080112 \\
\hline & DIANMU & 2016081800 & 2016081812 \\
\hline & MERANTI & 2016091312 & \\
\hline & AERE & 2016100600 & 2016100900 \\
\hline & SARIKA & 2016101512 & 2016101800 \\
\hline & HAIMA & 2016101912 & 2016102012 \\
\hline & TOKAGE & 2016112500 & 2016112700 \\
\hline & NOCK-TEN & 2016122600 & 2016122700 \\
\hline
\end{tabular}

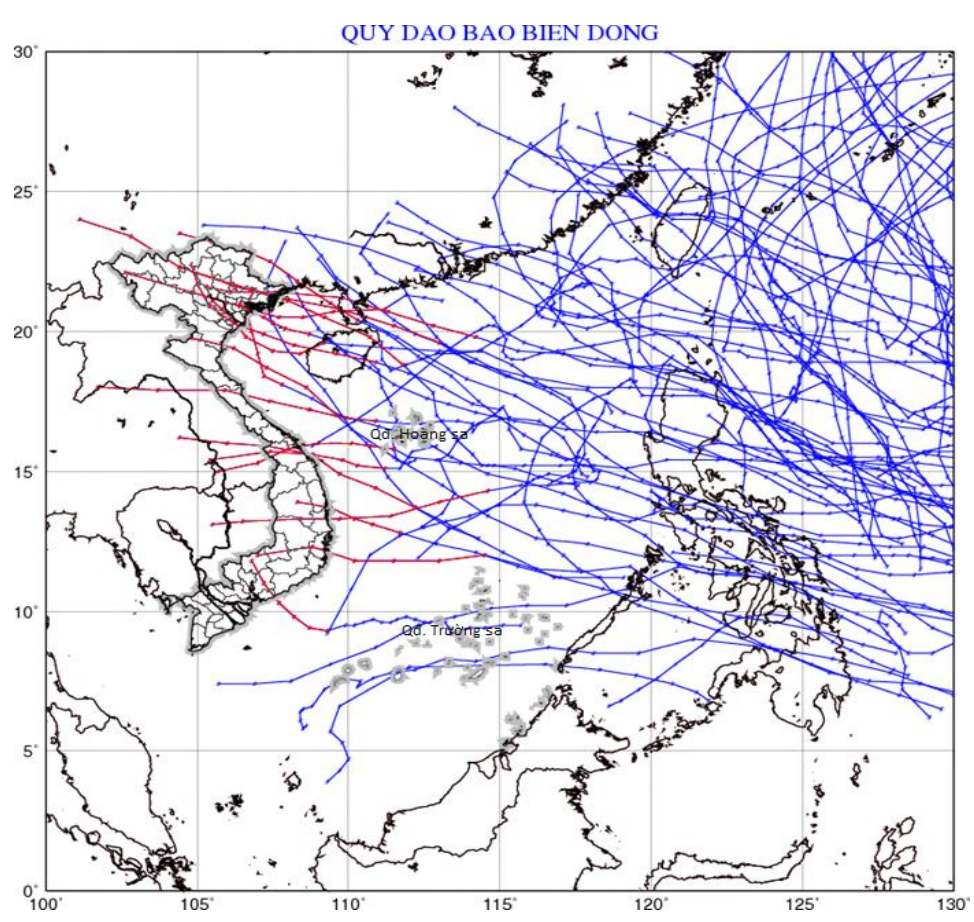

Hình 3. Quỹ đạo bão của các cơn bão được đánh giá trong giai đoạn 2012-2016.

\subsection{Các hệ thống dụ báo tổ hợp}

Được đưa vào nghiệp vụ từ những năm 2000, hệ thống dự báo tổ hợp khu vực tại Trung tâm Dự báo khí tượng thủy văn quốc gia được phát triển trên cách tiếp cận đa mô hình đa phân tích (Multi-Model Multi-Analysis) để xây dựng hệ thống dự báo tổ hợp thời tiết hạn ngắn cho khu vực Việt Nam-SREPS (Short-Range Ensemble Prediction System). Để đảm bảo việc tính toán được các nguồn bất định từ trường ban đầu (giả thiết rằng sự khác biệt trong các trường phân tích của các mô hình toàn cầu khác nhau mô tả các nguồn bất định trong trường ban đầu) và từ mô hình (giả thiết rằng các dự báo khác nhau được tạo ra bởi các 
mô hình số khu vực khác nhau sẽ mô tả nguồn bất định do mô hình). Các mô hình khu vực được sử dụng gồm WRF với nhân động lực $A R W$ (kí hiệu là WRF-ARW) và WRF với nhân động lực NMM (kí hiệu là WRF-NMM) và mô hình HRM. Các nguồn dự báo điều kiện biên khác nhau gồm mô hình GFS, GSM, GME, GEM và NOGAPS. Chi tiết về hệ thống SREPS được mô tả đầy đủ tại [5]. Dự báo SREPS được lưu trữ đến hạn $60 \mathrm{~h}$ nên các đánh giá trong nghiên cứu này chỉ thực hiện cho SREPS đến hạn 60 h. Từ năm 2010 , hệ thống SREPS từ năm có độ phân giải ngang xấp xỉ $16 \mathrm{~km}$. Cuối năm 2019, hệ thống SREPS được thay thế dựa trên toàn bộ việc sử dụng mô hình WRF-ARW với cấu hình đa vật lý, chi tiết có thể xem trong [11]. Từ cuối năm 2011, Trung tâm Dự báo khí tượng thủy văn quốc gia đã bắt đầu mua được số liệu dự báo toàn cầu, bao gồm sản phẩm tất định và tổ hợp từ Trung tâm dự báo hạn vừa Châu Ẩu (ECMWF) [12]. Hệ thống dự báo tổ hợp toàn cầu của ECMWF, kí hiệu là Var_EPS, bao gồm 51 thành phần dự báo. Hệ thống Var_EPS từ năm 2014 có độ phân giải ngang xấp xỉ $28 \mathrm{~km}$ và năm 2020 đã xuống còn $16 \mathrm{~km}$. Chi tiết về hệ thống Var_EPS được mô tả trong nghiên cứu "Nghiên cứu ứng dụng số liệu dự báo của Trung tâm Dự báo thời tiết hạn vừa Châu Âu để nâng cao chất lượng dự báo hạn tháng và hạn mùa cho khu vực Việt Nam" [12].

\section{Kết quả}

Trước hết, sai số quỹ đạo DPE của dự báo tất định và trung bình tổ hợp được tính toán và các kết quả được đưa ra tại các bảng 2-4. Các kết quả cho thấy rõ ưu điểm của dự báo quỹ đạo từ sản phẩm Châu Âu, từ dự báo tất định IFS, đến trung bình tổ hợp (EM). Sai số của các mô hình toàn cầu nằm trong khoảng từ $80-100 \mathrm{~km}$ đối với hạn $24 \mathrm{~h}, 100-150 \mathrm{~km}$ cho hạn dự báo $48 \mathrm{~h}$ và $150-250 \mathrm{~km}$ cho hạn $72 \mathrm{~h}$. Sai số của trung bình tổ hợp giảm từ 10-15\% so với dự báo tất định. Hai thành phần của hệ SREPS có sai số khá lớn, thậm chí lớn hơn khá rõ các mô hình toàn cầu. Đặc biệt thành phần WRF-ARW sử dụng điều kiện biên GSM và ngay bản thân mô hình GSM cũng cho sai số quỹ đạo khá lớn, thể hiện ở hạn 48h (Bảng 3). Sai số quỹ đạo từ mô hình GFS và GSM khi so sánh với hai thành phần WRF-GFS và WRF-GSM cho thấy vai trò của điều kiện biên từ mô hình toàn cầu là khá lớn trong bài toán dự báo quỹ đạo bão cho các mô hình khu vực. Trong đánh giá về kĩ năng dự báo cường độ bão trên khu vực Biển Đông [13] cho thấy thấy mặc dù các dự báo từ mô hình khu vực có thể cải thiện dự báo cường độ bão một cách rõ rệt, tuy nhiên dự báo quỹ đạo bão có kĩ năng thấp hơn so với các hệ thống toàn cầu. Nguyên nhân chủ yếu liên quan đến khả năng mô phỏng các tương tác quy mô lớn với bão tốt hơn trong hệ thống toàn cầu.

Bảng 2. Sai số dự báo các mô hình toàn cầu hạn $24 \mathrm{~h}$, và trung bình tổ hợp $(\mathrm{EM})$ của hai hệ thống dự báo toàn cầu (Var_EPS) và khu vực (SREPS).

\begin{tabular}{rccccccr}
\hline \multicolumn{1}{c}{ IFS } & GFS & GSM & $\begin{array}{c}\text { WRF- } \\
\text { GFS }\end{array}$ & $\begin{array}{c}\text { WRF- } \\
\text { GSM }\end{array}$ & $\begin{array}{c}\text { EM-Var- } \\
\text { EPS }\end{array}$ & $\begin{array}{c}\text { EM- } \\
\text { SREPS }\end{array}$ \\
\hline 2012 & 80,80 & 101,7 & 106,6 & 111,2 & 116,6 & 77,72 & 99,68 \\
2013 & 60,40 & 69,40 & 86,40 & 71,65 & 89,07 & 60,02 & 66,65 \\
2014 & 76,10 & 78,20 & 91,50 & 82,73 & 102,6 & 70,55 & 89,12 \\
2015 & 59,10 & 65,90 & 69,40 & 67,33 & 78,24 & 57,95 & 61,72 \\
2016 & 53,20 & 53,90 & 74,20 & 54,82 & 81,51 & 45,28 & 65,15 \\
\hline
\end{tabular}

Bảng 3. Tương tự bảng 2 nhưng cho hạn dự báo $48 \mathrm{~h}$.

\begin{tabular}{rccccccc}
\hline & & \multicolumn{7}{c}{ 48h } \\
\hline & \multirow{2}{*}{ IFS } & \multirow{2}{*}{ GFS } & GSM & $\begin{array}{l}\text { WRF- } \\
\text { GFS }\end{array}$ & $\begin{array}{c}\text { WRF- } \\
\text { GSM }\end{array}$ & $\begin{array}{c}\text { EM-Var- } \\
\text { EPS }\end{array}$ & $\begin{array}{c}\text { EM- } \\
\text { SREPS }\end{array}$ \\
\hline 2012 & 139,40 & 157,70 & 171,20 & 158,14 & 176,57 & 137,03 & 160,49 \\
2013 & 102,60 & 124,90 & 164,00 & 130,18 & 142,50 & 99,37 & 154,42 \\
\hline 2014 & 119,80 & 110,30 & 148,90 & 112,65 & 124,02 & 112,19 & 118,94
\end{tabular}




\begin{tabular}{rrrccccc}
\hline \multicolumn{10}{c}{ 48h } \\
\hline & \multirow{2}{*}{ IFS } & \multirow{2}{*}{ GFS } & \multirow{2}{*}{ GSM } & $\begin{array}{c}\text { WRF- } \\
\text { GFS }\end{array}$ & $\begin{array}{l}\text { WRF- } \\
\text { GSM }\end{array}$ & $\begin{array}{c}\text { EM-Var- } \\
\text { EPS }\end{array}$ & $\begin{array}{c}\text { EM- } \\
\text { SREPS }\end{array}$ \\
\hline 2015 & 126,60 & 155,00 & 121,50 & 159,95 & 125,64 & 119,85 & 139,90 \\
2016 & 82,40 & 108,40 & 163,90 & 112,76 & 171,82 & 79,55 & 128,59 \\
\hline
\end{tabular}

Bảng 4. Tương tự bảng 2 nhưng cho hạn dự báo $72 \mathrm{~h}$.

\begin{tabular}{rrrrc}
\hline & IFS & GFS & GSM & EM-Var-EPS \\
\hline 2012 & 295,30 & 237,70 & 243,50 & 286,97 \\
2013 & 174,20 & 236,60 & 160,00 & 167,10 \\
2014 & 161,40 & 188,40 & 143,70 & 153,74 \\
2015 & 160,30 & 202,70 & 174,70 & 154,08 \\
2016 & 163,50 & 220,80 & 86,20 & 156,80 \\
\hline
\end{tabular}

Đánh giá về kĩ năng dự báo xác suất của hai hệ SREPS và Var_EPS, hình 4 đưa ra chỉ số BS tính toán chi tiết ở từng thời đoạn $6 \mathrm{~h}$ một. Do sản phẩm SREPS chỉ có đến $60 \mathrm{~h}$ nên chỉ thực hiện đánh giá đến hạn này. Đối với hệ thống dự báo tổ hợp gồm 51 thành phần của Trung tâm hạn vừa Châu Ầu ECMWF, chỉ số $B S$ có giá trị trung bình từ $0,2-0,5$ cho các hạn đến $48 \mathrm{~h}$ và từ 0,5 đến 0,7 cho các hạn sau $48 \mathrm{~h}$. Trong $24 \mathrm{~h}$ đầu, kĩ năng dự báo từ các mô hình khu vực khá thấp, độ tán quá rộng so với thực tế xuất phát từ việc sử dụng các mô hình khác nhau và các điều kiện biên độc lập, khi đó tâm phân tích và tâm dự báo của SREPS có sự khác biệt rõ rệt ở hạn đến $24 \mathrm{~h}$. Tuy nhiên, kĩ năng dự báo ở hạn $48 \mathrm{~h}$ khá tương đương với kĩ năng của tổ hợp Châu Âu, nằm trong khoảng từ $0,4-0,6$. Ở thời hạn dự báo 3 ngày thấy rõ sự ổn định khi sử dụng thông tin từ hệ thống dự báo tổ hợp Châu Âu. Như vậy có thể thấy, thông qua đánh giá hệ thống SREPS, việc áp dụng phương pháp tổ hợp cho phép giảm sai số dự báo của từng thành phần và cho phép cung cấp được dự báo có độ tin cậy hơn với việc sử dụng từng thành phần riêng lẻ.

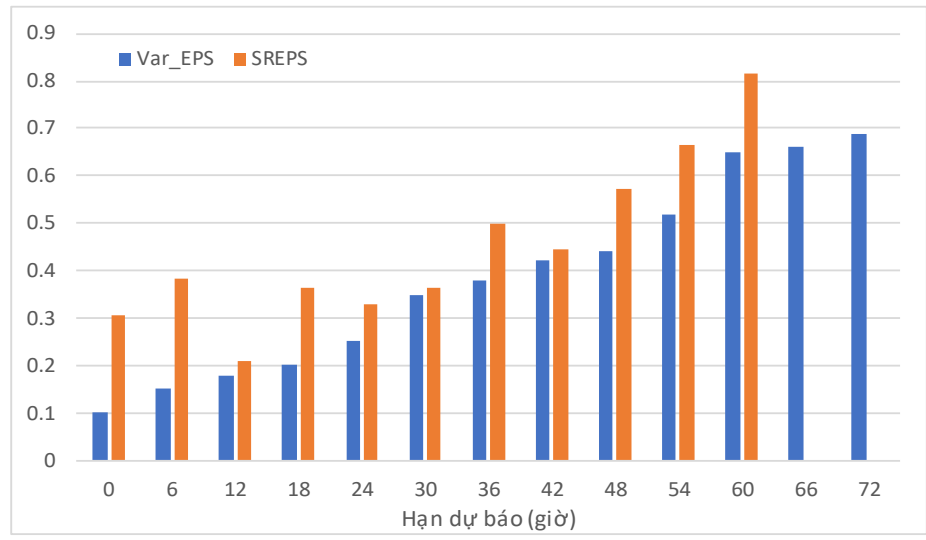

Hình 4. Chỉ số BS đánh giá kĩ năng dự báo xác suất theo hạn dự báo của hệ thống SREPS và Var_EPS giai đoạn 2012-2016.

\section{Kết luận}

Nghiên cứu đã trình bày phương pháp đánh giá kĩ năng dự báo quỹ đạo cho hệ thống tổ hợp sử dụng điểm số BS (Brier Score). Một số kết quả áp dụng cho hai hệ thống dự báo tổ hợp khu vực SREPS và tổ hợp toàn cầu của Trung tâm Dự báo khí tượng hạn vừa Châu Âu cho một số cơn bão hoạt động trên Biển Đông và ảnh hưởng đến lãnh thổ Việt Nam trong năm 2012-2016. Các kết quả đánh giá cho thấy, dự báo trung bình tổ hợp đối với cả khu vực và toàn cầu đều cho phép giảm sai số khi sử dụng dự báo quỹ đạo của từng thành phần đơn lẻ. Sai số của các mô hình toàn cầu nằm trong khoảng từ $80-100 \mathrm{~km}$ đối với hạn $24 \mathrm{~h}, 100$ $150 \mathrm{~km}$ cho hạn dự báo $48 \mathrm{~h}$ và $150-250 \mathrm{~km}$ cho hạn $72 \mathrm{~h}$. Đối với đánh đánh giá kĩ năng dự báo quỹ đạo, dự báo từ hệ thống tổ hợp toàn cầu ổn định và có kĩ năng hơn so với dự báo tổ 
hợp khu vực, đặc biệt ở hạn $24 \mathrm{~h}$ giờ đầu. Ở hạn $48 \mathrm{~h}$ có kĩ năng khá tương đồng, tuy nhiên ở hạn sau 48h, hệ thống toàn cầu cho thấy kĩ năng tốt hơn. Một trong những nguyên nhân ngoài việc số thành phần của hệ thống khu vực ít hơn so với toàn cầu, nguyên nhân chính còn nằm ở khả năng mô phỏng các tương tác quy mô lớn với bão tốt hơn trong hệ thống toàn cầu.

Đóng góp của tác giả: Xây dựng ý tưởng nghiên cứu: T.Q.N., T.T.T; Lựa chọn phương pháp nghiên cứu: T.Q.N., T.T.T.; Xử lý số liệu: T.Q.N.; Viết bản thảo bài báo: T.Q.N.; Chỉnh sửa bài báo: T.Q.N., T.T.T.

Lời cam đoan: Tập thể tác giả cam đoan bài báo này là công trình nghiên cứu của tập thể tác giả, chưa được công bố ở đâu, không được sao chép từ những nghiên cứu trước đây; không có sự tranh chấp lợi ích trong nhóm tác giả.

\section{Tài liệu tham khảo}

1. Kalnay, E. Atmospheric modeling, data assimilation and predictability. Cambridge University Press, Cambridge, 2003.

2. Toth, Z.; Kalnay, E. Ensemble forecasting at NCEP and the Breeding method. Mon. Wea. Rev. 1997, 125, 3297-3319. https://doi.org/10.1175/15200493(1997)125<3297:EFANAT>2.0.CO;2.

3. Palmer, T.N.; Monteni, F.; Mureau, R.; Buizza, R.; Chapelet, P.; Tribbia, J. Ensemble prediction. ECMWF Technical Memorandum, 1992, pp. 188.

4. Molteni, F.; Marsigli, C.; Montani, A.; Nerozzi, F.; Paccagnella, T. A strategy for high-resolution ensemble prediction. Part I: Definition of representative members and global-model experiments. Quart. J. Roy. Meteor. Soc. 2001, 127, 2069-2094. https://doi.org/10.21957/ckrej99i3.

5. Hòa, V.V. và cs. Nghiên cứu ứng dụng dự báo tổ hợp cho một số trường khí tượng dự báo bão. Báo cáo tông kết đề tài nghiên cứu khoa học cấp Bộ, 2007, 117tr.

6. Thanh, C. Dự báo quỹ đạo bão ảnh hưởng đến Việt Nam hạn 5 ngày bằng phương pháp tổ hợp, sử dụng kỹ thuật nuôi nhiễu. Luận án Tiến sĩ, Đại học Quốc gia Hà Nội, 2014.

7. Wilks, D.S. Statistical Methods in the Atmospheric Sciences, Academic Press, 2006, pp. 704.

8. Grijn, V.D. 2002. Tropical cyclone forecasting at ECMWF: New products and validation. ECMWF Tech. Memo. 2002, pp. 386.

9. Heming, J.T. Tropical cyclone ensemble forecast product development and verification at the Met Office. The $26^{\text {th }}$ Conference on Hurricanes and Tropical Meteorology, Miami, FL. Amer. Meteor. Soc. 2004, 5C.6.

10. Tiến, D.Đ. Khảo sát mối quan hệ giữa kĩ năng mô phỏng quỹ đạo bão và cường độ bão cho khu vực Tây Bắc Thái Bình Dương bằng hệ thống dự báo tổ hợp. Luận án tiến sĩ, Đại học quốc gia Hà Nội, 2017.

11. Tiến, D.Đ.; Cường, H.Đ.; Hưng, M.K.; Lâm, H.P. Đánh giá tác động của việc sử dụng tham số hóa đối lưu trong dự báo đợt mưa lớn tháng 7 năm 2015 trên khu vực Bắc Bộ bằng mô hình phân giải cao. Tạp chí Khí tượng Thủy văn 2019, 699, 1-8. https://doi.org/10.36335/VNJHM.2019(699).1-8.

12. Hòa, V.V. và cs. Nghiên cứu ứng dụng số liệu dự báo của Trung tâm Dự báo thời tiết hạn vừa Châu Âu để nâng cao chất lượng dự báo hạn tháng và hạn mùa cho khu vực Việt Nam. Báo cáo tổng kết đề tài NCKH cấp Bộ, 2016, 129tr.

13. Tiến, D.Đ.; Thành, N.Đ.; Chánh, K.Q.; Hằng, N.T. Khảo sát sai số dự báo và kĩ năng dự báo quỹ đạo và cường độ bão của các trung tâm dự báo và các mô hình động lực trên khu vực Biển Đông. Tạp chi Khi tương Thủy văn 2016, 661, 17-23. 


\title{
Skill validation of probability tropical cyclone track forecast in Bien Dong
}

\section{Tran Quang Nang ${ }^{*}$, Tran Tan Tien ${ }^{2}$}

${ }^{1}$ National Center for Hydrometeorological Forecasting; trannang030984@gmail.com;

${ }^{2}$ Ha Noi University of Science; tientt49@gmail.com

\begin{abstract}
This study presents the method of skill evaluating of probability forecast for tropical cyclone's track in Bien Dong by using the BS score (Brier Score). Some results apply to SREPS-a regional ensemble system (based on the WRF-ARW, WRF-NMM and HRM models, using multiple inputs GFS, GSM, GME, GEM, and NOGAPS) and the global ensemble system from European Center for Medium Meteorological Forecasting (ECMWF) for tropical cyclones operating in Bien Dong sea and affecting the territory of Vietnam in 2012-2016. The ensemble mean forecast allows for the reduction error in comparison with any individual member. The global ensemble system has more skill than regional ensemble system in term of probability forecast for tropical cyclone's tracks.
\end{abstract}

Keywords: Ensemble forecast for tropssical cyclone; Skill validation; SREPS; Var_EPS. 